\title{
K-WIDE: Synthesizing the Entrepreneurial Mindset and Engineering Design
}

\section{Prof. Charles Kim, Bucknell University}

Charles Kim is an associate professor of mechanical engineering at Bucknell University. He received Ph.D. and M.S.E. degrees from the University of Michigan and B.S. from Caltech. Prof. Kim teaches courses in design and innovation and is currently director of the Innovation, Design, Entrepreneurship, Applications, and Systems program at Bucknell.

\section{Prof. Joe Tranquillo, Bucknell University}

Joe Tranquillo teaches at Bucknell University, offering courses in signals and systems, neural and cardiac electrophysiology, instrumentation and medical device design. He has published widely on electrical dynamics in the heart and brain, biomedical computing, engineering design and engineering education. 


\title{
K-WIDE: Synthesizing the Entrepreneurial Mindset and Engineering Design
}

\begin{abstract}
It's winter break at Bucknell University and 23 first and second year engineers are tackling the National Academy of Engineering Grand Challenge, Restoring and Improving Urban Infrastructure. They have immersed themselves for 130 hours over 10 days, for no credit, and no pay. Their interdisciplinary teams have been challenged to identify their own problem. They will brainstorm possible solutions, and pick one to build. Then using all of the resources of the college, they build, refine and build some more. At the end of the tenth day there are six new products that will restore or improve urban infrastructure. They range from a simple addition to subway trains that would reduce noise levels by $20 \mathrm{~dB}$, to miniature waterwheels that could be installed all around a city to capture energy from running water, to a playground swing instrumented to charge mobile devices.
\end{abstract}

\section{Introduction}

The KEEN Winter Interdisciplinary Design Experience (K-WIDE) was born in 2012 out of a desire to provide undergraduate students with the opportunity to work in interdisciplinary teams to experience authentic design under real constraints. First and second year students were purposely targeted ${ }^{1}$, as they had not yet become too siloed in their individual disciplines. Anyone who wanted to be a part of the program could join. The program was offered during winter break when outside distractions (curricular or extra-curricular) were minimized. In addition, there was no formal credit, payment or grades and no industry sponsorship. This freedom allowed the instructors to try new teaching techniques and let the program evolve organically before, and even during, the program. One of the few requirements imposed on the students is that they would devote themselves completely to K-WIDE for the entire 10 days. What emerged was a visceral experience that students still speak about as "one of the most important experiences they had" in college.

Given the pilot of K-WIDE in 2012, the authors have had time to deconstruct and better articulate the goals and objectives of the program. The emergent goal of K-WIDE in 2012 was for students to grow in a number of mindsets and attitudes that would enable them to gain the most from the remainder of their time in college and beyond. In tackling a "Wicked Problem", one that is so multidimensional that the solution cannot come from one domain of practice, students began to explore how they might interact with the world as an engineer. This more clear understanding was then implemented in a more intentional second offering of K-WIDE in January 2014 to 17 second year engineering students from 5 different majors. 
In this paper we describe the themes that have emerged. In Section 2 we describe our two main theses: 1) that the design process can be taught through inductive learning and 2) that the synthesis of engineering design and the entrepreneurial mindset can take place in a program that lies somewhere between extra-curricular and curricular. Section 3 identifies six characteristic roles we hope our students will adopt, while Section 4 explains several objectives that support the six characteristics. Section 5 details the pedagogical themes and Section 6 outlines how student growth was assessed.

\section{Inductive Design and the Entrepreneurial Engineer}

Two themes arose from the 2012 version of K-WIDE that were only later identified by the authors. The first is learning the design process through induction. The second is a tight interweaving of the engineering design process and the entrepreneurial mindset.

\section{Inductive Learning of the Design Process}

The engineering design process is usually taught deductively - the abstract process is presented first, often in graphical form, and then assignments guide students through the various steps. The process may be as simple as the five-step process advocated by the Stanford d.school ${ }^{2}$ to the more complex process in engineering design textbooks that may have 10 or more steps ${ }^{3,4}$. All mention that feedback is necessary, but rarely show this feedback in the diagram. Although the process is claimed to be dynamic and adaptive, it is often not taught this way. As a result, students are given a technical problem to solve, and that problem is known to be solvable using the engineering design process. Teaching in this way constrains the kinds of problems that can be tackled by engineering students, but the advantage is that the instructor can control the timing and challenges students will face. The intent is for students to first learn a "clean" and theoretical design process which they will later update through further exposure, perhaps in senior design or after they graduate. The problem, however is that this static process does not work on real-world problems, especially those where more than technical design is needed.

The inductive learning movement ${ }^{5,6,7}$, challenges this paradigm by claiming that generalities do not come first, but rather emerge out of concrete experiences. Furthermore, concrete experiences often result in an increased desire to learn more. Inductive learning, however, is typically reserved for courses that are content heavy - a specific problem or challenge is given to the students and it is this problem that drives forward the learning of concepts.

In K-WIDE we experiment with teaching the design process through inductive learning. Toward that end, the textbook design process is never shown to the students. Instead they progress through various exercises to help them adopt perspectives and attitudes toward a problem (Sections 3 and 4). It is only at the end of the program that the formal design process is revealed. 
For the past several decades engineering design has been laid on a foundation of engineering science. The result is that technical rigor has been the measure of a competent engineer. While technical competence is clearly necessary, it is no longer sufficient ${ }^{8}$. Engineers produce the technologies that helps drive the economy forward ${ }^{9,10}$, but the constraints for design are coming from many directions that are non-technical ${ }^{11}$. ABET has long required programs to demonstrate that their engineering graduates have a broad understanding of the world around them. Many programs, however, struggle to integrate an awareness of the non-technical constraints on design that include social, political, environmental, global, ethical and economic forces.

In the past decade, there has been a movement toward integrating an entrepreneurial mindset into engineering design ${ }^{12,13,14,15,16}$. There are also several public (NSF Epicenter; epicenter.stanford.edu) and private foundations (KEEN; www.keennetwork.org, NCIIA; nciia.org, and Big Beacon; bigbeacon.org) advocating for entrepreneurship in engineering. The National Academy of Engineering has also recently published a high profile series of articles on entrepreneurship and innovation ${ }^{8}$. The claim of this movement is that entrepreneurship is a natural way for students to begin thinking about how engineering design is impacted by non-technical constraints and considerations.

The nature and components of the entrepreneurial mindset are both subjects of current debate. A great deal of data, however, does exist. From a theoretical perspective, entrepreneurship has been described as a process similar to the scientific method ${ }^{17}$ where business hypotheses are proven or disproven ${ }^{18,19}$. Ferguson and Ohland explain the entrepreneurial mindset as a theoretical multidimensional surface of personal characteristics, some innate and others learned ${ }^{20}$. Empirical studies have surveyed various stakeholders to determine the potential value of adopting an entrepreneurial mindset. For example, Duval-Couetil et al. have surveyed students to determine their attitudes toward entrepreneurship ${ }^{21}$ and Besterfield-Sacre et al. surveyed employers to develop a list of entrepreneurial competencies that form a Entrepreneurship Knowledge Inventory ${ }^{22}$. Other studies have focused more on entrepreneurial instruction ${ }^{16,23,24,25,26,27,28}$ and the perceptions of faculty teaching entrepreneurship ${ }^{29}$. Lastly, there are several studies exploring the synergies between engineering and entrepreneurship, ranging from including entrepreneurial competencies into core engineering classes ${ }^{30}$, to programmatic threads in entrepreneurship ${ }^{26}$, to the alignment of Entrepreneurship and $\mathrm{ABET}^{24}$.

K-WIDE integrates engineering design and entrepreneurship in a way that lies between formal instruction and competitions. On the one hand, K-WIDE operates outside of curricular requirements, in a similar manner to design competitions, business pitches, start-up weekends and other such student opportunities ${ }^{31}$. On the other hand, the end goal of K-WIDE is not a product but personal growth and learning. This aspect is more similar to a formal curriculum, and as a result there is a significant degree of guidance and instruction from the instructors.

\section{K-WIDE Characteristic Roles}

Throughout K-WIDE students were encouraged to be mindful of several different archetypal roles. The idea of an archetype was popularized by Carl Jung, but has been co-opted by several others. 
For example, De Bono created the Six Hats brainstorming technique ${ }^{32}$ to balance convergent and divergent thinking. Likewise IDEO has published the Ten Faces of Innovation that describes the key personnel of a creative and productive team ${ }^{33}$.

Six idealized roles emerged from K-WIDE. Some are more associated with engineering, while others are associated more with the entrepreneurial mindset. The goal for the student, however, is to be able to move fluidly between the roles as they navigate a complex and adaptive process. It was hoped that this rapid switching between roles would in fact enrich the individual archetypes as tensions and synergies are discovered. Students are encouraged to try to assume these roles and warned that some would feel more comfortable than others.

\section{Designer}

The designer is concerned with delighting the user by making their experience one of high value. They think about both form and function, both inside of the device and in the user interface. A good designer will have internalized some version of Design Thinking - a broad term that includes technical engineering design ${ }^{34,35}$. There are several flavors of design thinking, best exemplified by the Stanford d.school (dschool.stanford.edu), MIT Media Lab (www.media.mit.edu), and design firms such as IDEO (www.ideo.com), Innocentive (www.innocentive.com) and Synapse (www.synapse.com).

\section{Project Manager}

The project manager is concerned with how to organize resources to their maximum effect so that tasks can be achieved. These tasks may span from simple to complex and from individual to team-based. Every project will have limited resources and a good project manager will be able to fluidly allocate people, time, money, equipment, space and other resources of a group. A good project manager will also be able to break down and clearly communicate the tasks to be done both globally and for individuals ${ }^{36}$.

\section{Maker}

The maker creates prototypes to think, prove, communicate and gain information that will inform design decisions. The maker also possesses a theoretical understanding that guides them in making choices before, during and after building. Through experience, the maker knows how hard a technical task will be and what resources are needed to build. The maker may be a part of the Maker Movement (makerfaire.com, makezine.com, arduino.cc, www.sparkfun.com) that has lowered the technological barriers to the non-expert ${ }^{37}$.

\section{Professional}

The professional can identify and communicate strengths and weaknesses, in themselves and others. They have an understanding of a hierarchy of goals and can accept differences in opinions and 
goals, even when those goals are not in alignment. They make forward progress through timely decisions, strategic compromises and coordinated actions. The professional will expand or contract to fill the roles that are needed on a team ${ }^{38}$.

\section{Role Model}

The role model is searching for continuous growth in themselves and the team around them. They do not lead in the traditional sense but rather gain the respect of those around them through selfefficacy ${ }^{39,40,41}$ a growth mindset ${ }^{42}$ and intrinsic motivation - characteristics of what Jim Collins

describes as the "Level 5" or Enlightened Leader ${ }^{38}$. They learn from their own failures ${ }^{43}$ and encourage others to learn from theirs. They motivate others by appealing to their autonomy, mastery and purpose ${ }^{44}$.

\section{Value Creator}

The value creator can identify areas where value is lacking and then acts to fill the gaps. They apply this attitude to themselves, their team and the world around them. The value creator is critical of the outcomes of their work, but paradoxically can remain positive about the progress made $^{45,8}$.

\section{Educational Objectives}

The educational objectives in K-WIDE directly articulate the synthesis of engineering design and the entrepreneurial mindset facilitated by the program. In Section 3 we presented 6 characteristic roles that K-WIDE students are challenged to assume. In general, the Designer, Project Manager, and Maker are typically associated with engineering design, while the Value Creator, Professional, and Role Model are associated with the entrepreneurial mindset. These divisions, however, become blurred at the level of educational objectives. K-WIDE educational objectives are listed in Table 1 and are mapped to the relevant roles. Some of the objectives map only to roles related to the entrepreneurial mindset or engineering design. For example, progress in reflection and the growth mindset are typically associated with the entrepreneurial mindset. Many of the objectives, however, map to roles related to both the entrepreneurial mindset and engineering design.

In this remainder of this section, we give short descriptions of how particular objectives capture this synthesis by considering the objectives from multiple perspectives. This will clarify the intent of some of these objectives, while also providing a link to the characteristic roles described earlier. To that end, we highlight three of the objectives - Problem Identification, Decomposition, and Navigating 5-50,000 feet. 
Table 1: K-WIDE objectives mapped to characteristic roles (Designer, Project Manager, Maker, Role Model, Professional, Value Creator)

\begin{tabular}{|c|c|c|c|c|c|c|}
\hline Objective (as connectors) & $\mathrm{D}$ & $\mathrm{PM}$ & M & RM & $\mathrm{P}$ & $\mathrm{VC}$ \\
\hline $\begin{array}{l}\text { Problem Identification: Identify problems in any situation } \\
\text { (Look at the world differently) }\end{array}$ & $\overline{\mathrm{X}}$ & & & & & $\mathrm{X}$ \\
\hline $\begin{array}{l}\text { Decomposition: Decompose a solution into smaller tractable } \\
\text { sub-problems and articulate goals }\end{array}$ & $\mathrm{x}$ & $\mathrm{x}$ & & & & $\mathrm{x}$ \\
\hline $\begin{array}{l}\text { 5-50,000: Navigate a problem between } 50,000 \mathrm{ft} \text { to } 5 \mathrm{ft} \text { lev- } \\
\text { els. (Why, who, where, what, how) }\end{array}$ & $\mathrm{x}$ & & & & $\mathrm{x}$ & $\mathrm{x}$ \\
\hline $\begin{array}{l}\text { Prototyping: Utilizing physical prototypes to make design } \\
\text { decisions. }\end{array}$ & $\mathrm{X}$ & & $\mathrm{x}$ & & & \\
\hline $\begin{array}{l}\text { Reflection: Critically reflect utilizing multiple forms of com- } \\
\text { munication }\end{array}$ & & & & $\mathrm{X}$ & & $\mathrm{x}$ \\
\hline $\begin{array}{l}\text { Growth Mindset: Consider personality traits, talents, and in- } \\
\text { telligence as dynamic and subject to growth. }\end{array}$ & & & & $\mathrm{X}$ & & $\mathrm{X}$ \\
\hline $\begin{array}{l}\text { Communication: Communicate ideas/concepts to diverse } \\
\text { audiences in multiple modalities. }\end{array}$ & $\mathrm{X}$ & $\mathrm{X}$ & & & $\mathrm{x}$ & \\
\hline $\begin{array}{l}\text { Collaboration: Effectively collaborate in [multidisciplinary] } \\
\text { teams [of students, faculty, staff, and outside constituents] }\end{array}$ & $\mathrm{x}$ & $\mathrm{X}$ & & $\mathrm{X}$ & $\mathrm{x}$ & \\
\hline $\begin{array}{l}\text { Generate, evaluate, and select concepts from multiple alter- } \\
\text { natives. }\end{array}$ & $\mathrm{x}$ & & $\mathrm{x}$ & & & $\mathrm{x}$ \\
\hline
\end{tabular}

\section{Problem Identification}

The Designer focuses on translating a real-world problem into the language of engineering, distilling needs down to specifications. Various design methodologies (e.g. Quality Function Deployment $^{46}$, objective trees ${ }^{3}$ ) exist to generate a list of measurable engineering specifications to determine the quality of a design solution.

The Value Creator on the other hand views problem identification as finding where maximum value can be achieved. The exercise of identifying problems is to recognize opportunity and to frame them in terms of potential societal impact, and profitability.

These two views of problem identification are in fact complementary and require overlapping skill sets. The task of problem identification broadly requires the ability to recognize need and to translate relatively ambiguity to manageable terms that can be understood by different audiences.

\section{Decomposition}

Both the Designer and the Project Manager break down complex technical problems into more tractable sub-problems. An essential step in the design process is the articulation of sub-problems divided by functions that the final product must accomplish. Functional decomposition ensures that the Designer initially maintains independence of tasks for simplicity ${ }^{47}$. Moreover, functional 
decomposition helps to identify critical-to-quality features of a design, which in turn facilitates focus.

The Value Creator views problem decomposition through a different lens. The Value Creator recognizes opportunity and must then break down the identified problem along the lines of market segments to focus the problem according to what directions may bring the greatest value. The Value Creator must identify subproblems that would be relevant stakeholders including marketing, manufacturing, packaging, distribution, and customer support.

\section{Navigating 5-50,000 ft}

In a 5-50,000 foot paradigm, the combined skills and mindset of the Designer and the Value Creator are truly synthesized. At 50,000 feet, the Value Creator considers why a problem needs to be addressed. Relevant questions include: In the context of broader societal, global, and economic issues, why is this problem important to solve? Moving to a lower "elevation," the Value Creator considers more specifically who will be affected by the solution. At 30,000 feet, one must consider where the solution must be implemented. At 25,000 feet, the Designer questions "What must the product do?" Going down further in "elevation" the Designer asks questions such as "what will this feature do," and eventually arrives at "how will we accomplish this with a specific embodiment?"

Navigating the 5-50,000 foot paradigm requires consistent, repeated divergent-convergent thinking and intentional reflection on how decisions made at lower elevations address questions at 40,000 to 50,000 feet. Decisions and constraints interact at different elevations, requiring a holistic understanding of the entire scope of a problem. The entrepreneurial-mindset and engineering design meet in a single paradigm. There must be direct connection between decisions made as a Designer to the considerations important to the Value Creator.

\section{A vertical view of the Designer and Value Creator}

Moving down the columns of Table 1 reveals a different perspective on the characteristic roles. The descriptions in Section 3 are augmented now by actions that can be taken by each of the roles. For example, the Designer can identify problems, decompose problems into more tractable subproblems, navigate the 5-50,000 foot paradigm, prototype to make design decisions, communicate, collaborate, and generate and select concepts.

At a deeper level, the vertical view of Table 1 highlights a very tight relationship between the Designer and the Value Creator. Both must possess a firm grasp of a similar set of objectives, but must do so in distinct yet overlapping ways. One of the emergent themes of the K-WIDE program is that it synthesizes the entrepreneurial mindset and engineering design. In K-WIDE, the Designer and Value Creator co-exist and synergize, and the objectives articulate this. 


\section{Pedagogical Approach}

In the educational community, entrepreneurship has been referred to as an extreme sport. The key implication of the analogy is that entrepreneurship must be experienced to be learned in a meaningful way. Because K-WIDE is a synthesis of the entrepreneurial mindset and engineering design, it is natural to adopt an experiential learning model that more closely resembles best practices in teaching entrepreneurship - experiences first, general principles thereafter. We employ a multi-faceted pedagogical approach that includes three distinct elements. These elements are: (1) hands-on design-build-test-refine, (2) total immersion, and (3) critical reflection. While no one of these elements is absolutely necessary to achieve the educational objectives, their combination yields a unique approach to teaching engineering design where the design process arises organically from experience rather than a typical textbook approach.

\section{Hands-on Design-Build-Test-Refine}

Engineering design cannot be divorced from physical realization. There are few (if any) virtual exercises that can replace a fabricated prototype to reveal implications of design decisions while also increasing student investment when compared to a paper design. Physical prototyping exposes overcomplexity, conceptual blindspots, and deficient planning. From a more positive perspective, students learn to communicate and think through prototyping to prove out concepts, principles, and form. Students learn the imperative of design details and the difference between a viable virtual prototype and model that simply cannot be built. Much of engineering is doing, so it was important in K-WIDE to incorporate a full hands-on design-build-test-refine cycle. This affords participants practice in communicating and thinking through prototyping, recognizing the limitations of initial concepts, experiencing and learning through tangible failure, and hopefully desiring more of it even after the program was complete.

\section{Total Immersion}

Most courses during the academic year follow essentially the same model - formal contact hours during class and independent work outside of class spread over a relatively long period of time. Assignments do not usually occur immediately before or after instruction and there is much time during a semester or quarter for course material to sink in.

This may not be the only (or best) way to teach design. We intentionally stage K-WIDE to occur off-semester when students have no other curricular or extra-curricular commitments. Winter break is ideal because peers are no longer on campus, and other college resources are liberated from their normal commitments during the academic year and the summer months. What results is something that is hard to create almost anywhere let alone a campus usually bustling with activity - no distractions.

The proximity of experience and instruction is of critical importance. In K-WIDE, design occurrs in concentrated spurts over a very short period of time overall. Formal lecture is minimal, and most instruction is just-in-time in consultation and reflection with individuals, teams, and as a 
larger group. Failure is tangible and common and has to be addressed on the spot. With the shortened overall time-frame, students develop greater emotional attachment to both their success and learning ${ }^{48}$. We propose that the immersive nature of the K-WIDE program facilitates deep learning despite the short overall time-frame of the experience.

\section{Critical Reflection}

As described by the Kolb Cycle ${ }^{49}$, critical reflection is an essential element of experiential learning. In the Experiential Learning Model (Figure 1), concrete experience is supported by reflective observation and abstract conceptualization. Learning does not occur simply through having a concrete experience; the experience must be processed to become "sticky." Furthermore, experiences must be generalized and framed in terms of broader principles so that learning can be extended beyond a particular experience. In critical reflection, we capture what Kolb refers to as reflective observation and abstract conceptualization by encouraging (i) summation of the experience, (ii) generalization to broader concepts, (iii) connection between the experience and the concept, (iv) application to the current experience, and (v) extension to future situations.

Most students are accustomed to summarizing experiences, but few are accustomed to generalizing to broader principles and extending what they've learned to other experiences. To help students grow in the practice and mindset of critical reflection, we allocate specific times during the program for students to do nothing else but critically reflect. This reflection takes on many different forms with scaffolded levels of faculty instruction. Some reflective exercises are standard individual written assignments, while others are discussed as groups or sketched for all participants to see. All exercises are processed together in the larger group to reinforce common themes and to encourage deeper, more critical reflection. Finally, it is important in the program for instructors to model good behavior; we not only share reflections on our own past failures and successes, but are constantly reflecting on the program with the students.

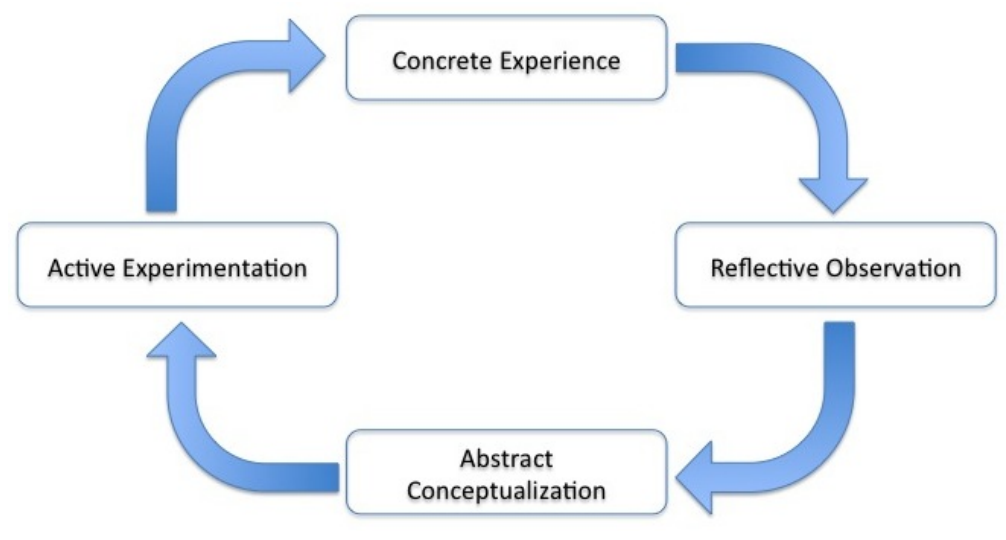

Figure 1: Kolb cycle for experiential learning 
What arose from the hands-on, immersive, and reflective environment was a flipped approach to teaching engineering design where the process was experienced and generalized. Each of these aspects were not completely necessary to do teach design in this way, but they help to amplify the combined effect in leading students to a deeper understanding of design. Teaching in this way warps teaching the traditional design process in two ways. First, design concepts are seen from many other points of view and reinforced. Second, the design process itself is discovered, not taught.

As mentioned earlier, design is often presented as a sequence or progression of steps that begin with the identification of a problem and result in the creation of a new product or idea. When articulated in this way, the engineering design process parallels the scientific process by intention. Engineering design is framed as a hypothesis-driven activity, almost in a deterministic fashion with claims that following the process will (always) yield a viable solution.

As in scientific discovery, this description of engineering design is too simple. It fails to communicate the messiness of effective convergent-divergent, global thinking. Absent from such representations are broader, vital considerations such as economic, societal, global, and environmental issues. In the name of generality, nuance is obscured and with it the mindset and attitude necessary to design successfully.

\section{Assessment}

K-WIDE was originally intended to be an experimental program where some new pedagogy could be tested. As such, no formal assessment was conducted in the first offering (January 2012). Instead the first offering allowed for a number of themes to arise, as detailed in Sections 2-5. In the January 2014 offering, formal assessment was conducted, as outlined in the IRB-approved studies below. The demographics used in the analysis below are shown in Table 2.

Table 2: Demographics of the Two Offerings of K-WIDE

\begin{tabular}{|c|c|}
\hline January $\mathbf{2 0 1 2}$ & January 2014 \\
\hline 13 male and 10 female & 8 male and 9 female \\
\hline 7 first year, 16 second year & 17 second year engineers \\
\hline 5 engineering departments & 5 engineering departments \\
\hline 6 international students & 3 international students \\
\hline
\end{tabular}

There were no final assignments to grade so the instructors gained insight by comparing how individual student perceptions changed throughout the program. More formally, we followed a qualitative research methodology known as Grounded Theory ${ }^{50}$. In grounded theory pilot data is collected, not with the purpose of refining methodology, but to discover the themes that should be further explored. These data are then used to construct the appropriate assessment techniques. The assessment below was only applied to the 2014 offering of K-WIDE. 
The goal of the student surveys (Appendix B) is to gain insight into how students perceive they have grown during K-WIDE. Measuring this growth has two components. First, students must have an accurate measure of where they were when the program started. This is often difficult to measure given that students may not fully understand some of the key terms in the survey (e.g. growth mindset). Students took the survey before the program began (Pre-survey). They then took the survey again after K-WIDE, but reflected back on their state before the program started (Pre-Adjusted). They did not have access to their previous scores and therefore had to rely on their own perception of their past skills and attitudes. The students took the survey a third time after the program was finished (Post-survey). A comparison of the Pre- and Post-Survey allowed the researchers to assess growth in the traditional fashion. Comparison of the Pre-Adjusted and Post-survey allowed the researchers to gain a more accurate measure of the student's perception of growth and a measure of student self-efficacy.

The aggregated results of the survey are shown in Tables 3 and 4. Table 3 shows results from survey questions regarding student perception of ability. These questions are related to K-WIDE objectives and assess whether the students have grown in their ability to "do." Students report growth in all skill areas. This is remarkable considering the number of skill areas assessed and the short time frame students had in the program. The "Post - Pre-Adjusted" differences are, in general, larger than those in the "Post-Pre" columns. This would seem to suggest that students have either gained a greater understanding of the topics or have increased in their self-efficacy.

Table 4 shows results from questions related to mindset. Some questions pertain to the growth mindset, while others test whether students have adopted a design thinking mindset (5-50,000 $\mathrm{ft}$ ). Again, students report positive change toward a growth mindset and broader design thinking. These data also seem to suggest that students have grown in their own self-awareness. For example, students more strongly agreed with the statement "Failure is constructive and has the potential to make me better" at the completion of K-WIDE. What is more is that students perhaps recognized that they may not have agreed with the statement as much as they had reported when K-WIDE started (Post - Pre $=0.11$, Post - PreAdjusted $=0.78)$. Similar trends can be found in results from many of the other questions.

These data suggest that students perceive growth in their abilities as engineering designers in the context of entrepreneurial product development. Not only that, but they have grown in their self-efficacy in relation to their mindset (e.g. growth mindset and design thinking).

\section{Coding of Student Reflections}

During K-WIDE, students were asked to reflect in written, oral and graphical forms for approximately 20 minutes per day. As the reflections occurred between the pre and post surveys, they provide a way to observe growth during K-WIDE. Here we focus our results on the graphical reflections, where we used methodologies from social networking ${ }^{52,53}$, as shown in Figure 3 . To code for structure (Figure 3 A,B and D), matrices were created that reflect the network structure of the diagram. Once in matrix form, several network measures were applied ${ }^{52}$. These measures 
Table 3: Perceived growth in ability levels. Results are shown for Post vs. Pre and Post vs. PreAdjusted surveys. $\mathrm{N}=9$

\begin{tabular}{|c|c|c|}
\hline Rate your present ability level for the following topics. (1 - Beginner, 5 - Expert) & Post - Pre & Post - PreAdjusted \\
\hline Identify technical problems from background research and/or direct experience & $\overline{1}$ & 1.22 \\
\hline Identify business opportunity from current state of the market & 1.33 & 1.33 \\
\hline Divide a technical problem into small tractable sub-problems and articulate goals of the sub-problems. & 1.11 & 1.22 \\
\hline Use prototypes as a way to iterate, evaluate, and critique design concepts. & 1.33 & 1.55 \\
\hline Use fabrication techniques to create physical prototypes & 1.11 & 1.33 \\
\hline Express an idea through appropriate written, graphical, and/or oral communication. & 0.89 & 0.78 \\
\hline Prepare and deliver an appropriate communication for a specific audience. & 0.78 & 1 \\
\hline Delegate tasks according to technical competencies, background, and/or personality. & 1 & 1.22 \\
\hline Provide and respond to constructive criticism on a task. & 0.23 & 0.89 \\
\hline Articulate design goals of sub-problems and frame them in terms impact on overall design goals. & 1.44 & 1.66 \\
\hline Value and leverage the skills of a members of a team to achieve a design goal. & 1.11 & 1.33 \\
\hline Use information from inside and outside of a team to make design decisions. & 1 & 1.33 \\
\hline Generate multiple alternatives for a given design goal with real world constraints and limited information. & 1.33 & 1.44 \\
\hline Systematically evaluate and select the best solution based real world constraints and limited information. & 1.12 & 1.45 \\
\hline Articulate why a problem is important before determining how it will be solved. & 1 & 1.45 \\
\hline Frame the quality of a design solution in terms of economic, political, societal, environmental, and ethical impact. & 1.33 & 1.11 \\
\hline Assess if a design trajectory is appropriate based on who the solution will affect and why it's important to them. & 1.33 & 1.33 \\
\hline Communicate critical reflection in multiple ways (written, graphical, oral). & 1 & 1.22 \\
\hline
\end{tabular}

Table 4: Questions to measure mindset change. Results are shown for Post vs. Pre and Post vs. Pre-Adjusted surveys. $\mathrm{N}=9$

\begin{tabular}{|c|c|c|}
\hline Indicate your level of agreement with the following statements. (1 - Strongly Disagree, 5 - Strongly Agree) & Post - Pre & Post - PreAdjusted \\
\hline Failure is negative and should be avoided. & -0.56 & -0.78 \\
\hline Failure is constructive and has the potential to make me better. & 0.11 & 0.78 \\
\hline I have experienced failure and learned from it. & 0.11 & 0.56 \\
\hline I am naturally good at certain things. & 0.22 & 0.33 \\
\hline I am naturally bad at certain things and can't change that. & -0.22 & -0.33 \\
\hline Being a good engineer is about being technical proficient. & -0.22 & -0.11 \\
\hline An understanding of the wider world is necessary to design a product. & 0.23 & 0.34 \\
\hline Reflection takes time which could be better used to get things done. & -1.11 & -0.78 \\
\hline I value learning things when I spend time thinking about what I have done in the past. & 0.11 & 0.33 \\
\hline I usually spend enough time looking for connections between topics and broader concepts. & 0.33 & 0.56 \\
\hline $\begin{array}{l}\text { During concrete experiences, it is valuable to connect the causes and effects (who, what, where, how, why) of } \\
\text { decisions I make. }\end{array}$ & 0.23 & 0.56 \\
\hline It is valuable to reflect on past success and failures so that I can apply what I've learned to new sit & 0.12 & 0.34 \\
\hline
\end{tabular}


were applied to diagrams created by the students before and mid-way through the program.

Sixteen diagrams of the design process were collected before the program and all were used in the analysis. Seventeen diagrams of the design process were collected at the mid-point of the program, but only 12 were used for analysis. The five that were removed were too far removed from the design process and focused instead on the personal journey of the individual. Although these were informative, and in many cases complimented results from the post surveys, they were not of a similar type to the pre-sketches.

On average there were 8.6 nodes (represented by distinct boxes that reflect steps in the design process) in initial diagrams compared to 13.4 in the diagrams sketched mid-way through K-WIDE. The average number of edges (represented by arrows) between nodes also increased from 17 to 26.5 throughout the program. While an increase in edges is expected with an increase in nodes, the network distance between nodes in fact decreased from 6.1 before to 5.6 at the mid-way point (measured by network diameter). This decrease is striking because it means that even with more nodes being added to the diagram, the average distance between the steps decreased. The average degree of each node, however, remained relatively constant at 2.16 before and 2.19 afterward, meaning that the average node was connected to roughly two other nodes. The maximum eigencentrality measures how influential the most connected node is within a network. The eigencentrality for the most well-connected node rose from 0.44 before to 0.46 afterward, meaning that the most well connected node was only slightly more well connected mid-way through the program. In other words, the basic network structure did not change (i.e. changing from tree-like to a hub network).

Although formal coding of the topics within the diagrams was not conducted, the anecdotal evidence is that the nodes that were added in were not simply traditional design topics. Some examples are reflection, consideration of economic impact, value to society, and marketability. A future study will code for content in both the written and graphical reflections, where $\operatorname{codes}^{51}$ would coming from the themes presented in Sections 3-5.

These results show that structurally students retained the traditional linear backbone of design, as presented in many design textbooks, but were adding in tasks from outside of traditional design and key feedback loops as needed for their projects.

\section{Discussion}

\section{Our Specific Implementation}

One of the goals of this paper is to demonstrate that our approach is one possible way to effectively synthesize engineering design and the entrepreneurial mindset in an educational context. We have intentionally focused on the broader pedagogical philosophy that informed development of the K-WIDE program. The practical details of how to run a program like K-WIDE have been specifically omitted from the paper to focus on themes and pedagogy. Information about what principles guided the specific implementation of K-WIDE can be found in two online resources. First, a general set of practical guidelines on how to conduct an immersive experience like K-WIDE has 
(A)

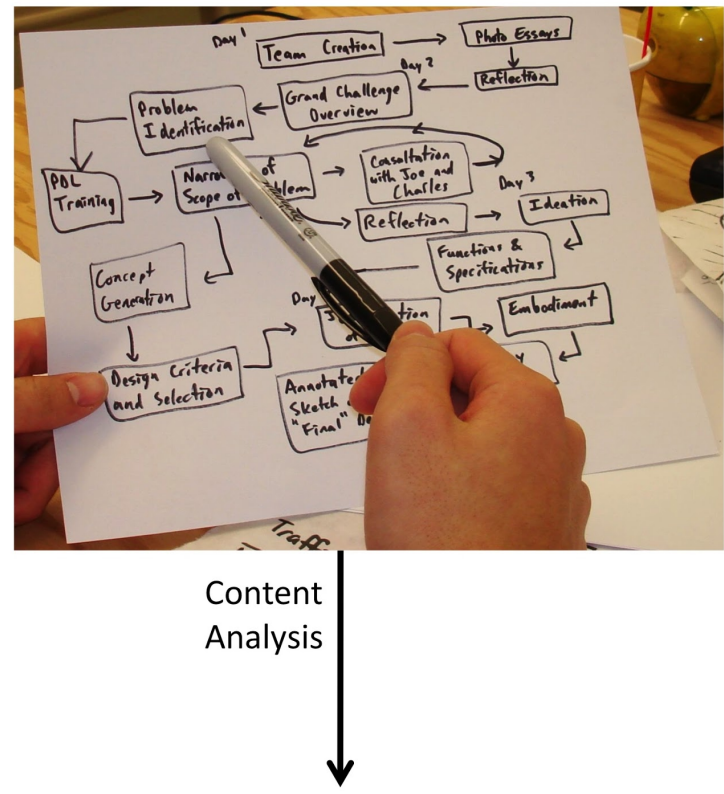

Six Roles (Section 3)

(C) Objectives (Section 4)
(B)

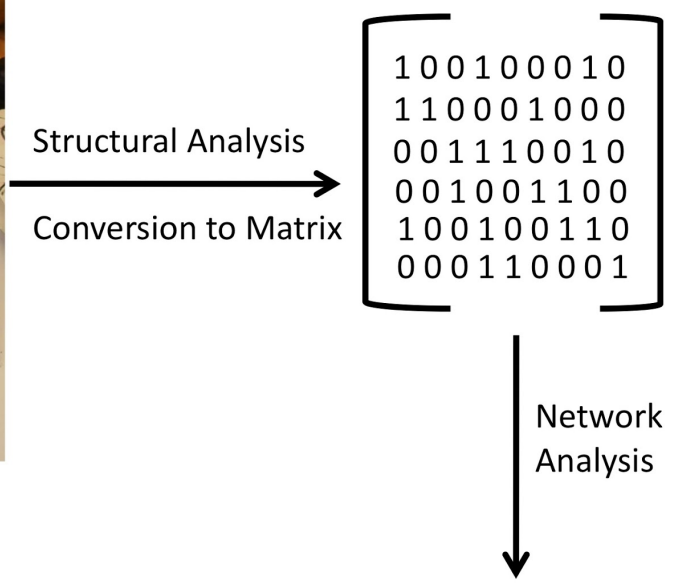

Clustering Coefficient

Eigen Centrality

Degree Distribution

(D) Density

Distance

Figure 2: Network measures of graphical reflections 
been recorded in an article by on the EpiCenter website (epicenter.stanford.edu/resource/designbootcamp-joe-tranquillo-bucknell-university). Second, highlights of the 2012 offering of the program were captured in a video (http://www.youtube.com/watch?v=TCrprLHndCI).

The specific implementation of the program described in these two resources is not the only way to achieve the educational objectives described in Section 4. What the implementation encouraged, though, was a freedom that allowed us to pursue new teaching techniques. Furthermore, it allowed elements and characteristics of the program to evolve organically during both planning and implementation of K-WIDE.

Future work along these lines is to implement K-WIDE at other universities. To that end, we have agreements from three universities to consider our model and implementation and to create and offer their own version by January 2015. Offerings of K-WIDE at the other schools will give us a better sense of what variables can and should be modified and still achieve the educational objectives.

\section{Limitations}

The current study is limited in several ways. First, K-WIDE has only been implemented twice at one school, with two instructors, during a specific and unique time during the year. To overcome this limitation, three other schools, each with their own instructional team, will offer a version of K-WIDE in the next calendar year. Second, the assessment was limited in the same way - only data from one offering was included, with the first offering serving to identify and clarify themes. The 2014 assessment presented here is therefore, a pilot of the methodology to assess student growth in the areas discussed in Sections 2-5. A modified version of this assessment will be used by the three additional schools and these data will be presented at a later date. Third, the validation of the survey questions used only local experts. This concern will be partially addressed when K-WIDE is adopted by other schools.

\section{Questions and Future Work}

There are some wider questions surrounding K-WIDE that warrant further work; we highlight three in particular. First, more exploration on teaching design using inductive teaching methods appears to be warranted. Similar to other studies on inductive teaching, a key question will be the effectiveness relative to other methods, both in the long and short term. Second, K-WIDE was offered to only $10 \%$ of our student body. As sophomores, we exposed them to elements of design but interwoven with the entrepreneurial mindset. The individual disciplinary approach to design that they will be exposed to later in their curricula are in many cases not in alignment with this approach. Anecdotally, the 2012 K-WIDE alumni have related to us the tension they have felt between the two approach and so we question the students' abilities to productively synthesize both experiences. Perhaps a further study could compare the total design experience of 2012 K-WIDE alumni as compared to other design students. Third, it is not clear whether a 10-day immersive program can have a long-term impact on students during their four-year course of study. The survey and reflection coding did not measure long-term attitudinal impact. It may 
be possible to administer the Post-survey (Appendix B) to members of the 2012 K-WIDE program as well as students of a similar demographic who were not part of K-WIDE. The authors have had little formal contact with the K-WIDE alumni, so a comparison of the two cohorts may be used to measure the potential long-term effects of K-WIDE. Lastly, the 2012 version of K-WIDE started with the Grand Challenge of Restoring and Improving Urban Infrastructure. The 2014 version was targeted at Human Weight. It is not clear if such broad challenges are necessary to run K-WIDE.

\section{Conclusion}

The two main themes of this paper are that: (1) teaching engineering design and the entrepreneurial mindset can and should be synthesized in a synergistic manner and (2) an inductive approach to teaching the engineering design process can aid in galvanizing a more complex, nuanced understanding of a flexible design process. Combining the inductive approach to teaching engineering design with an emphasis on the entrepreneurial mindset adds a richness that can be lost when either is taught alone. This synthesis is clearly articulated at the level of educational objectives where characteristic roles of the Designer and Value Creator strongly overlap and together provide a more holistic approach to problems. The preliminary assessment data suggest that this approach shows promise to addresses both of the main themes and warrants further investigation.

\section{Acknowledgement}

The authors gratefully acknowledge the support of the Kern Family Foundation under the grant titled "Diffusion of K-WIDE."

\section{References}

[1] Reid and Ferguson. Enhancing the entrepreneurial mindset of freshman engineers. In American Society for Engineering Education Annual Conference, 2011.

[2] URL http://dschool.stanford.edu/wp-content/uploads/2011/03/BootcampBootleg2010v2SLIM.pd

[3] Dym and Little. Engineering design: A project-based introduction. Wiley, New York, 2004.

[4] David Ullman. The mechanical design process. McGraw-Hill, 1992.

[5] Michael J. Prince and Richard M. Felder. The many faces of inductive teaching and learning. Journal of College Science Teaching, 36(5), 2007.

[6] Borrego, Maura, Froyd, and Hall. Diffusion of engineering education innovations: A survey of awareness and adoption rates in us engineering departments. Journal of Engineering Education, 99(3):185-207, 2010.

[7] Ken Bain. What the best college teachers do. Harvard University Press, 2011. 
[8] Byers, Seelig, Sheppard, and Weilerstein. "entrepreneurship: Its role in engineering education". The Bridge. National Academy of Engineering, 43(2), 2013.

[9] Rover. New economy, new engineer. Journal of Engineering Education, 94(4), 2005.

[10] Schumpeter. The Theory of Economic Development. Transaction Publishers, 2004.

[11] Wei. Engineering education for a post-industrial world. Technology in Society, 2, 27.

[12] Nichols and Armstrong. ngineering entrepreneurship: Does entrepreneurship have a role in engineering education?". IEEE Antennas and Propagation Magazine, 45(1):134-138, 2003.

[13] Kreiwall and Mekemson. Instilling the entrepreneurial mindset into engineering undergraduates. Journal of Engineering Entrepreneurship, 1, 2010.

[14] Menzel, Aaltio, and Ulijn. On the way to creativity: Engineers as intrapreneurs in organizations. Technovation, 27(12):732-743, 2007.

[15] Luthje and Franke. The making of an entrepreneur: Testing a model of entrepreneurial intent among engineering students at mit. $R$ and D Management, 33(2), 2004.

[16] Creed, Suuberg, and Crawford. Engineering entrepreneurship: An example of a paradigm shift in engineering education. Journal of Engineering Education, 91(2):185-195, 2002.

[17] Neck and Green. Entrepreneurship education: Known worlds and new frontiers. J of Small Business Management, 49(1), 2011.

[18] Fiet. The theoretical side of teaching entrepreneurship. Journal of Business Venturing, 16:1-24, 2000.

[19] Osterwalder and Pigneur. Business model generation: a handbook for visionaries, game changers, and challengers. Wiley, 2010.

[20] Ferguson, Cawthorne, Edwin, Ahn, and Ohland. Engineering innovativeness. The Journal of Engineering Entrepreneurship, 4(1):1-16, 2013.

[21] Duval-Couetil, Reed-Rhoads, and Haghighi. The engineering entrepreneurship survey: An assessment instrument to examine engineering student involvement in entrepreneurship education. The Journal of Engineering Entrepreneurship, 2(2):35-56, 2011.

[22] Besterfield-Sacre, Ozaltin, Robinson, Shuman, Shartrand, and Weilerstein. Factors related to entrepreneurial knowledge in the engineering curriculum. The Journal of Engineering Entrepreneurship, 4(1):31-38, 2013.

[23] Davis and Rose. Entrepreneurial engineering capstone course with research-based outcomes assessment. 114th Annual ASEE Conference and Exposition, 12, 2007.

[24] Duval-Couetil, Wheadon, Kisenwether, and Tranquillo. Entrepreneurship and abet accreditation: How and where does it fit? In Frontiers in Education Conference, pages 134-136. IEEE, 2013.

[25] Gerber, McKenna, Hirsch, and Yarnoff. Learning to waste - wasting to learn? how to use cradle to cradle principles to improve the teaching of design. International Journal of Engineering Education, 2010.

[26] Ochs, Lennon, Watkins, and Mitchell. A comprehensive model for integrating entrepreneurship education and capstone projects while exceeding abet requirements. In American Society for Engineering Education Annual Conference, 2006.

[27] Petersen, Jordan, and Radharamanan. Proposed keen initiative framework for entrepreneurial mindedness in engineering education. In American Society for Engineering Education, 2012.

[28] Rasmussen and Sorheim. Action-based entrepreneurship education. Technovation, 26(2), 2006.

[29] Zappe, Hochstedt, Kisenwether, and Shartrand. Teaching to innovate: Beliefs and perceptions of instructors who teach entrepreneurship to engineering students. Int J of Eng Ed, 2013. 
[30] Schar. Bending moments to business models: Integrating an entrepreneurship case study as part of core mechanical engineering curriculum. In American Society for Engineering Education Annual Conference, 2013.

[31] Miller, Walsh, Hollar, Rideout, and Pittman. Engineering and innovation: An immersive start-up experience. Computing Now, pages 24-32, 2011.

[32] Edward De Bono. Serious creativity. Harper Business, 1995.

[33] Thomas Kelley and Jonathan Littman. The ten faces of innovation: IDEO's strategies for defeating the devil's advocate and driving creativity throughout your organization. Random House Digital, 2006.

[34] Dym et al. Engineering design thinking, teaching, and learning. Journal of Engineering Education, 94(1): 103-120, 2005.

[35] Byers and Dorf. Technology ventures: From idea to enterprise. McGraw-Hill Higher Education, 2008.

[36] Smith. Engineering project management. Blackwell Science, 2002.

[37] Wolf, Marco, and McQuitty. Understanding the do-it-yourself consumer: Diy motivations and outcomes. AMS review, 2011.

[38] Collins. Good to great: Why some companies make the leap and others don't. HarperCollins, 2001.

[39] Bandura. Self-efficacy: Toward a unifying theory of behavior change. Psychological Review, 84, 191-215., 84: 191-215, 1977.

[40] Sherer, Maddux, Mercandante, Prentice-Dunn, Jacobs, and Rogers. The self-efficacy scale: Construction and validation. Psychological Reports, 51(2), 1982.

[41] Gerber, Martin, Braunstein, Kramer, and Carberry. Innovation self efficacy: Development of a measure. Frontiers in Education, 2012.

[42] Carol Dweck. Mindset: The New Psychology of Success. Ballatine Books, 2007.

[43] Gerber. Students must be taught to fail. US News and World Report, November 23, 2012 November 23, 2012 November 23, 2012.

[44] Daniel Pink. Drive: the surprising truth about what motivates us. Riverhead Books, 2009.

[45] Standish-Kuon and Rice. Introducing engineering and science students to entrepreneurship: Models and influential factors at six american universities. Journal of Engineering Education, 91(1), 2002.

[46] Y. Akao, editor. Quality Function Deployment: Integrating Customer Requirements into Product Design. Productivity Press, 1990.

[47] Otto and Wood. Product Design: Techniques in Reverse Engineering and New Product Development. Prentice Hall, 2001.

[48] Damasio. Descartes' error: Emotion reason and the human brain. Penguin, 2005.

[49] Kolb. Experiential learning: Experience as the source of learning and development. Vol. 1. Prentice Hall, 1984.

[50] Creswell. Qualitative inquiry and research design: Choosing among five approaches. Sage, 2012.

[51] Saldana. The Coding Manual for Quantitative Researchers. Sage, 2009.

[52] Newman. Networks. Oxford University Press, 2010.

[53] McLinden. Concept maps as network data: Analysis of a concept map using the methods of social network analysis. Evaluation and Program Pla, 36(1):40-48, 2013. 


\section{APPENDIX A - Learning Outcomes}

This appendix contains the learning outcomes linked to each of the educational objectives presented in Section 4.

\section{Problem Identification: Identify problems in any situation (Look at the world differently)}

Identify problems in any situation (Look at the world differently)

Articulate the importance (and difficulty) of identifying and defining a design problem.

Identify customer-appropriate value proposition

Perform background research on existing problems

Perform background research on existing solutions

Generate a list of viable problems without coming up with a design solution

\section{Decomposition: Decompose a solution into smaller tractable sub-problems and articulate goals}

Identify primary and supporting functions necessary for solving an open-ended problem

Identify primary functions of an artifact

Decompose primary functions into supporting functions

Explain the manufacturability of the components of a device

5-50,000: Navigate a problem between 50,000 ft to $5 \mathrm{ft}$ levels. (Why, who, where, what, how)

Explain technical and non-technical dimensions of a problem

Include economic, political, social, environment and ethical factors in performing background research on a problem

Include economic, political, social, environment and ethical factors in selecting a problem

Include economic, political, social, environment and ethical factors in designing a device

Articulate breaking up a 50,000 foot problem into many interrelated problems at a lower level

List the potential for positive and negative value at the 50,000 foot level of solving a problem.

\section{Prototyping: Utilizing physical prototypes to make design decisions.}

Combine together physical ways of achieving functions to form alternative solutions

Prepare and submit a materials order

Demonstrate that the physical embodiment of a solution concept is viable (feasibility)

Evaluate physical implementations of achieving a function 
Construct a prototype

Deliver a prototype / proof-of-concept presentation

Using engineering fabrication techniques to achieve a designed function.

\section{Reflection: Critically reflect utilizing multiple forms of communication}

Speak reflectively, using supporting stories, about the K-WIDE experience

Write reflectively by summation, generalization, and extension

Synthesize a concrete design experience and communicate different elements of the design process in a sketch.

Recognize the importance of interdisciplinary design in engineering today and the future.

Produce reflections that are graphical in nature.

Create and tell personal stories of their design experiences

Briefly discuss the K-WIDE program with a lay audience

Growth Mindset: Consider personality traits, talents, and intelligence as dynamic and subject to growth.

Recognize failure (as constructive) and extract a wider/broader principle and come up with a plan to act upon it.

Identify unexpected opportunity from failure.

Recognize the areas of strength that positively impact the achievement of a team goal

Reframe goals when existing goals become unrealizable.

Use constructive feedback from technicians to revise an on-paper design

Articulate the benefits of concurrent engineering in relationship to interdisciplinary design.

Recognize the areas of personal growth after an experience

Use a physical prototype as a means of reflecting on a design solution.

Communication: Communicate ideas/concepts to diverse audiences in multiple modalities.

Update a design based upon a formal design review

Create an annotated sketch of a design idea

Provide a rationale for design decisions

Record comments from technicians for later revision

Present a sketch to a technicians

Draft a final sketch of a design

Explain an anticipated end point for a project

Sell a design concept in the format of a poster 
Incorporate a live demonstration into a presentation

Present for impact in a short time format

Prepare and present a plan, including delegation of tasks, for concluding a project

Articulate customer-appropriate value proposition

Collaboration: Effectively collaborate in multi-disciplinary teams of students, faculty, staff, and outside constituents

Equitably delegate tasks to be completed

Identify what you can bring to a team naturally and what you need to work on to effectively work with others.

contribute to a group brainstorming session

participate in making team decisions about goals and the process of achiving those goals.

invite and work with outside experts to gain information that is needed to achieve goals.

Take on a leadership role in acheiving a team goal

Generate, evaluate, and select concepts from multiple alternative

List several methods of brainstorming

Generate ideas using divergent methods of brainstorming

List multiple ways of achieving a function

Define evaluation criteria

Select an alternative solution

Refine alternative solutions

Provide rationale for design decisions

Iterate on an annotated sketch

Perform a feasibility study.

\section{Appendix B - Qualtrics Survey Questions}

Rate your present ability level for the following topics. Options: Not Sure/Beginner/Somewhat Competent/Competent/Advanced/Expert

- Identify technical problems from the background research in the state of technology.

- Identify business opportunities from the state of the market and frame in terms of value creation.

- Divide a technical problem into small tractable sub-problems and articulate goals of the sub-problems.

- Articulate design goals of sub-problems and frame them in terms impact on overall design goals.

- Use prototypes as a way to iterate, evaluate, and critique design concepts

- Use fabrication techniques to create physical prototypes 
- Express an idea through appropriate written, graphical, and/or oral communication

- Prepare and deliver an appropriate communication for a specific audience

- Delegate tasks according to technical competencies, background, and/or personality.

- Provide and respond to constructive criticism on a task

- Value and leverage the skills of a members of a team to achieve a design goal

- Using information from inside and outside of a team to make design decisions

- Generate multiple alternatives for a given design goal with real world constraints and limited information

- Systematically evaluate and select the best solution based real world constraints and limited information

- Articulate why a problem is important before determining how it will be solved

- Frame the quality of a design solution in terms of economic, political, societal, environmental, and ethical impact.

- Assess if a design trajectory is appropriate based on who the solution will affect and why it's important to them.

- Communicate critical reflection in multiple ways (written, graphical, oral)

Indicate your level of agreement with the following statements Options: Strongly Disagree/Disagree/Neither Disagree or Agree/Agree/Strongly Agree

- Being a good engineer is about being technical proficient

- An understanding of the wider world is necessary to design a product

- Failure is negative and should be avoided.

- Failure is constructive and has the potential to make me better.

- I have experienced failure and learned from it

- I am naturally good at certain things

- I am naturally bad at certain things and can't change that.

- Reflection takes time which could be better used to get things done

- I value learning things when I spend time thinking about what I have done in the past

- I usually spend enough time looking for connections between topics and broader concepts

- During concrete experiences, it is valuable to connect the causes and effects (who, what, where, how, why) of decisions I make

- It is valuable to reflect on past success and failures so that I can apply what I've learned to new situations.

How important are the following when considering the quality of a design solution? Options: Very Important/Important/Not Important

- Economic impact

- Societal impact

- Political impact

- Environmental impact

- Ethical impact

- Manufacturability 
- Cost

- Failure

- Innovativeness

- Feasibility

- Functionality

- User interface 